\title{
Petroleum Science and Technology
}

\section{A Study on Flow Characteristics of Heavy Crude Oil for Pipeline Transportation}

\section{J. Zhang, J.-Y. Xu \& X.-P. Chen}

To cite this article: J. Zhang, J.-Y. Xu \& X.-P. Chen (2015) A Study on Flow Characteristics of Heavy Crude Oil for Pipeline Transportation, Petroleum Science and Technology, 33:13-14, 1425-1433, DOI: $10.1080 / 10916466.2015 .1070175$

To link to this article: http://dx.doi.org/10.1080/10916466.2015.1070175

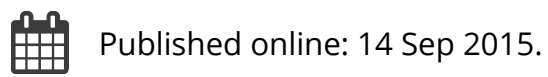

Submit your article to this journal $\sqsubset$

Q View related articles ๘

View Crossmark data ¿ 


\title{
A Study on Flow Characteristics of Heavy Crude Oil for Pipeline Transportation
}

\author{
J. Zhang, ${ }^{1}$ J.-Y. Xu, ${ }^{1}$ and X.-P. Chen ${ }^{1}$ \\ ${ }^{1}$ Institute of Mechanics, Chinese Academy of Sciences, Beijing, China
}

\begin{abstract}
In this work, the flow characteristics of heavy crude oil were investigated by using a rheometer and a lab scale flow loop, respectively. In the experiments of rheometer, there is an approximate linear relationship between the yield stress and the area of thixotropic loop independent to the system temperature and crude oil types. A comparison between the experimental data of yield stress versus start-up rate obtained in the pipe start-up flow with those measured in the rheometer reveals that the transport characteristics of heavy crude oil can be predicted well by the rheological measurements.
\end{abstract}

Keywords: heavy crude oil, pipeline transportation, thixotropy, yield stress, flow characteristics

\section{INTRODUCTION}

Heavy crude oil can demonstrate nearly the complex rheological behaviors compared to light crude oil, such as shear-thinning, thixotropy, yield stress, and viscoelasticity (Martinez-Palou et al., 2011). Here, the thixotropy reflects the memory-dependent properties. Namely that the viscosity of thixotropic fluid undergoes an instantaneous drop to a lower value followed by the length of shear time. Therefore, it affects inevitably the pressure required to reinitiate in pipe flow. The thixotropic characteristic can be identified and measured by the transient stress techniques such as hysteresis loop and creep experiment. The study of Mortazavi-Manesh and Shaw (2014) shows that the magnitude of thixotropic characteristic of the Maya crude oil become larger as the temperature decreased, and the relationship between thixotropy and temperature can be expressed by the hysteresis loop area and the stress decay. By studying the apparent viscosity of thixotropic liquid, Escudier and Presti (1996) concluded that the apparent viscosity in pipe flow is far from structural equilibrium and always lower than the corresponding value obtained from the rheometer.

Yield stress is another important rheological behavior in the pipeline transportation of heavy crude oil (Barnes, 1999). The yield characteristics of heavy crude oil have to be taken into account in the design of the pipeline transportation because the value of yield stress is always bigger than the corresponding pressure in the pipe flow. In most cases, the stress-strain data are extrapolated to zero-shear rate, and the intercept on the ordinate is taken to be the yield stress. In the last half century, a number of rheological models have been used to study the yield stress, such as Bingham model, Herschel-Bulkley model, and Casson model. The results show that both the apparent viscosity and yield stress obtained by these models are largely dependent to the shear rate and decreases exponentially with increasing the temperature.

Address correspondence to J.-Y. Xu, Institute of Mechanics, Chinese Academy of Sciences, Beijing 100190, China. E-mail: xujingyu@imech.ac.cn. 


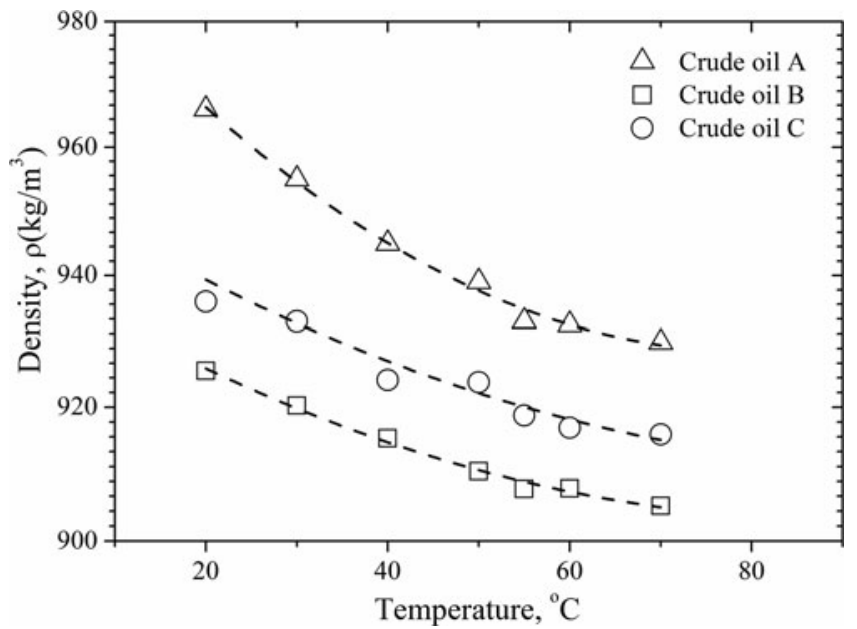

FIGURE 1 Temperature versus density of heavy crude oil in the range from 20 to $70^{\circ} \mathrm{C}$.

Although the rheological behaviors of heavy crude oil have attracted a lot of attention in the past, much research is still required urgently in order to fully understand these properties and the mechanisms behind it (Dehkissia et al., 2004). In order to extend the knowledge of the thixotropy and yield stress of heavy crude oil, we have carried out this work. Research results may be helpful to design or improve the pipeline transportation of heavy crude oil.

\section{EXPERIMENTAL}

\subsection{Materials}

Three kinds of heavy crude oil used in this work came from the Bo-hai oilfield in China. The origin of these samples was recognized by identifying them with letters A, B, and C. Crude oil A was taken from Sui-zhong oil processing plant, and crude oils B and $\mathrm{C}$ were obtained from oil-producing wells named V104 and V102, which are located in Jin-zhou oil processing plant, respectively. The crude oil density along with the change of temperature is shown in Figure 1. It can be seen that the density of heavy crude oil decreases with increasing the temperature.

\subsection{Rheological Measurement}

Rheological measurement was carried out on the Haake RS6000 Rheometer with a coaxial cylinder sensor system (Z38 DIN, gap width $=2.5 \mathrm{~mm}$ and sample volume of $\left.30.8 \mathrm{~cm}^{3}\right)$. In the rheometer, the liquid temperature-controlled units can make the sensor system reach to a fixed temperature and maintain this temperature throughout the experiment. In the thixotropy measurement, the hysteresis loop was obtained by increasing the shear rate from 0 to $300 \mathrm{sec}^{-1}$ and then decreasing to 0 continuously. In addition, the yield stress was measured by a vane-type rotor FL22 (diameter = $40 \mathrm{~mm}$, four vanes, gap width $=1.5 \mathrm{~mm}$ ), and four shear rates of $0.005,0.01,0.05$, and $0.1 \mathrm{sec}^{-1}$ were chosen to investigate the influence of shear rate on the yield stress. 


\subsection{Pipe Flow Experimental Setup and Procedure}

In the flow loop, the pipe with $47 \mathrm{~mm}$ inner diameter was made of stainless steel with the absolute roughness of $0.2 \mathrm{~mm}$, and the total length was about $15 \mathrm{~m}$. Two gauge pressure transducers (Rosemount $3051 \mathrm{TG}$ ) with accuracy of $0.15 \%$ were used to measure the fluctuation of pressure in the pipe at two different locations. The pressure gradient was measured by a differential pressure transducer (Rosemount $3051 \mathrm{CD}$ ) with the accuracy of $0.15 \%$. In addition, the Coriolis mass flowmeter, Micro Motion F050 from Emerson, was used to monitor the density, temperature, and mass flow rate.

The temperature was governed by the heating system in the oil tank and electric trace heating system along the entire pipe, respectively. The flow rate was controlled by the frequency converter of the pump and measured by the gear flow meter. In the start-up experiments, prior to the tests the flow loop was filled with heavy crude oil at a constant temperature. And then, the pump was started to force the heavy crude oil movement. At the same time, the flow rate, pressure gradient, and temperature were recorded to obtain the corresponding start-up parameters.

\section{RHEOLOGICAL CHARACTERISTICS}

\subsection{Rheograms of Heavy Crude Oil}

The flow behavior of heavy crude oil was investigated over a wide range of shear rates from 0 to 300 $\mathrm{sec}^{-1}$ under different temperatures. The measurement was carried out under the CR model. Here, the shear rate was set and the corresponding shear stress obtained. According to the results of previous study (Zhang et al., 2014), Ostwald de Waele model, Bingham model and Casson model can be used to analyze the rheological characteristics of heavy crude oil. Three models can be defined, respectively as

$$
\begin{array}{r}
\tau=m \cdot\left(\gamma^{\prime}\right)^{n} \\
\tau=\tau_{0}+\mu_{a} \cdot \gamma^{\prime} \\
\tau=\left(\tau_{0}^{0.5}+\left(\gamma^{\prime} \cdot \mu_{a}\right)^{0.5}\right)^{2}
\end{array}
$$

Here, $\tau$ is the shear stress in Pa and $\gamma^{\prime}$ the shear rate in $\sec ^{-1}$. In Eq. (1), $m$ and $n$ are consistency index in $\mathrm{Pa} \cdot \mathrm{sec}^{\mathrm{n}}$ and flow behavior index, respectively. In Eqs. (2) and (3), $\mu_{a}$ is apparent viscosity in $\mathrm{Pa} \cdot \mathrm{sec}$ and $\tau_{0}$ refers to the apparent yield stress in $\mathrm{Pa}$, and reflects the yield characteristics.

Figure 2 gives the effect of temperature on the viscosity at a fixed shear rate. The results show that the viscosity decreases when increasing the temperature in an exponential type, which performs the similar rule of Arrhenius model.

\subsection{Thixotropic Behavior}

Figure 3 gives the effects of temperature on the thixotropic loop area of crude oils A, B, and C under the same measurement conditions. It can be found that the thixotropic characteristic of crude oil A is always greater than those of oils $\mathrm{B}$ and $\mathrm{C}$ as a result of the different constituents including saturate, aromatic, resin and asphaltene. Although the crude oils $\mathrm{B}$ and $\mathrm{C}$ were produced from the same oil field, the thixotropic loop area of crude oil $\mathrm{C}$ shows a slight bigger than crude oil B. With increasing the temperature, the differences among three crude oils are weakened. That is to say that the heating can make the thixotropic behavior of heavy crude oil disappeared. 


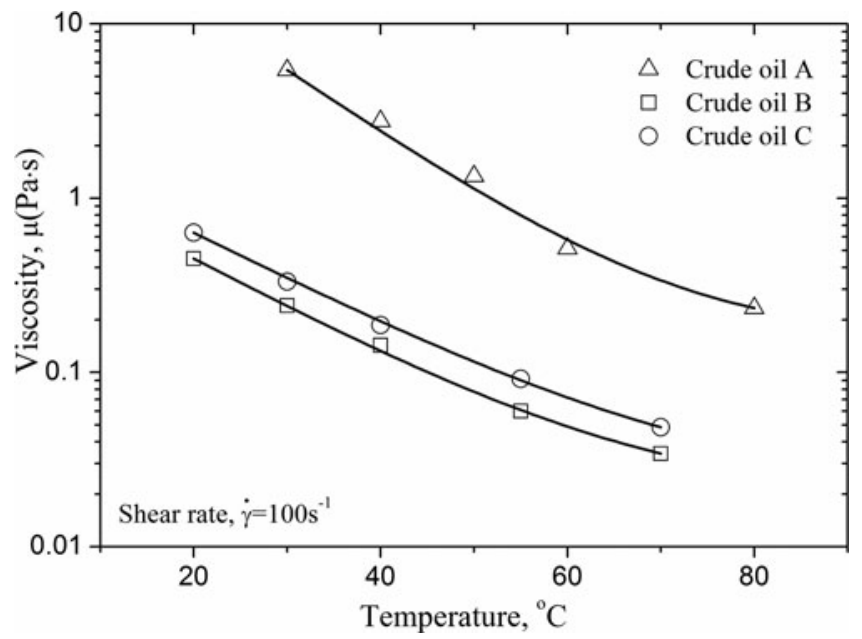

FIGURE 2 Temperature versus viscosity of heavy crude oil at a constant shear rate of $100 \mathrm{sec}^{-1}$.

\subsection{Yield Behavior}

Figure 4 gives the effect of shear rate on the yield stress for heavy crude oils $\mathrm{A}, \mathrm{B}$, and $\mathrm{C}$ at the temperature of $30^{\circ} \mathrm{C}$. Generally, the yield stress becomes larger with increasing the shear rate, and all curves show a linear relationship. Similar to the thixotropic property, the yield stress of crude oil $\mathrm{A}$ is always greater than that of crude oil $\mathrm{C}$, and the crude oil $\mathrm{C}$ greater than the crude oil $\mathrm{B}$ under the same conditions. In addition, the yield stresses obtained by Bingham model and Casson model are also presented in Figure 4 by using solid line and dotted line. It can be observed that the yield stresses extrapolated are close to those measured at high shear rates. Figure 5 displays the effect of temperature on the yield stress at a constant shear rate of $0.05 \mathrm{sec}^{-1}$. Three heavy crude oils display



FIGURE 3 Temperature versus area of thixotropic loop under the same measurement conditions. 


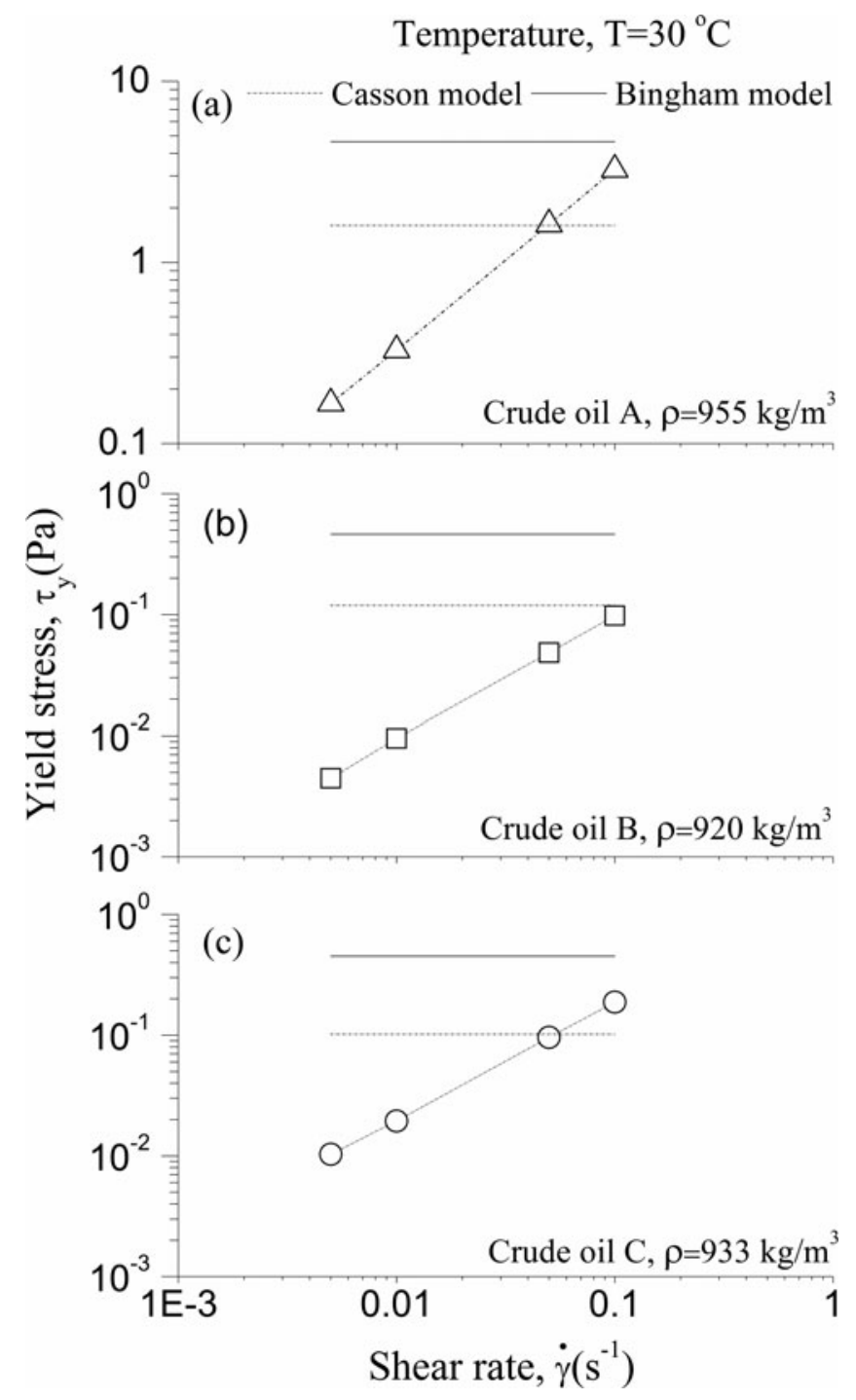

FIGURE 4 Yield stress versus shear rate for three different samples at $30^{\circ} \mathrm{C}$.

the rule of exponential decay, namely that the yield stress decreases exponentially with increasing the temperature. Combined with Figure 3, it can be seen that the change of thixotropic loop area with temperature is similar to that of yield stress. Therefore, the yield stress versus thixotropic loop area for three crude oils in the range of temperature from 20 to $70^{\circ} \mathrm{C}$ is plotted in Figure 6 . Interestingly, there is an approximate linear relationship between the yield stress and thixotropic loop area independent to the temperature and crude oil types. This finding may be helpful for solving the yield stress by measuring the thixotropy loop area. 


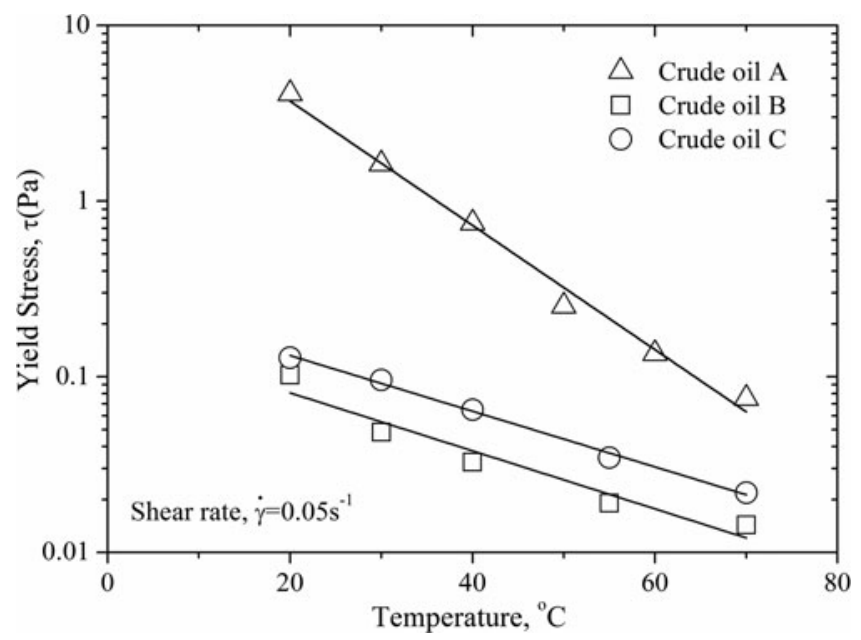

FIGURE 5 Yield stress versus temperature for three different samples at a constant shear rate of $0.05 \mathrm{sec}^{-1}$.

\section{PIPE FLOW MEASUREMENTS}

In a fully developed and steady flow of incompressible fluid in a pipe, the shear stress at the wall of the pipe is related to the frictional pressure drop $(\Delta P / L)$ by the following equation:

$$
\tau_{w}=D / 4 \cdot(\Delta P / L)
$$

here, $D$ is the diameter of the pipe. The friction factor is given as

$$
f=D /\left(2 \rho_{m} \cdot \mu_{m}^{2}\right) \cdot(\Delta P / L)
$$

here, $\rho_{m}$ is the mixture density and $u_{m}$ the average velocity of the fluids.



FIGURE 6 Yield stress versus area of thixotropic loop for three crude oils in the range of the temperature from 20 to $70^{\circ} \mathrm{C}$. 




FIGURE 7 Shear stress measured at the pipe wall versus time in the pipe start-up flow at four different start-up rates.

The shear rate at the wall for Power law fluid in a laminar flow can be obtained as

$$
\gamma^{\prime}=32 Q /(\pi D) \cdot[(1+3 n) / 4 n]
$$

where $Q$ is the mixture flow rate. Thus, the shear stress and shear rate can be calculated from the frictional pressure drop versus flow rate measurement.

\subsection{Yield Characteristics in Start-Up Pipe Flow}

In this study, the heavy crude oil A was chosen for the experiments in the pipe flow. The start-up pipe flow of crude oil A was simulated by measuring the pressure fluctuation from static to normal flow. The shear stress and shear rate at the wall of pipe were calculated from the pressure gradient and fluid velocity.

Figure 7 gives the change of shear stress at the wall against the time from static to normal flow with four different start-up rates of 35.99, 70.35, 134.15, and $162.96 \mathrm{~s}^{-1}$, respectively. As be shown, these curves can be divided into three stages including the static stage, start-up stage and normal flow stage. Initially, the shear stress is equal to zero, and then shows a sudden increase in a relatively short time. After that, the shear stress performs a little decrease and downs to a steady value. In this process, there is a peak point, which is defined as the yield point or start-up point. Through this point, the fluid starts to flow. Furthermore, it can be also seen that the value of shear stress at the yield point becomes larger with increasing the shear rate. 


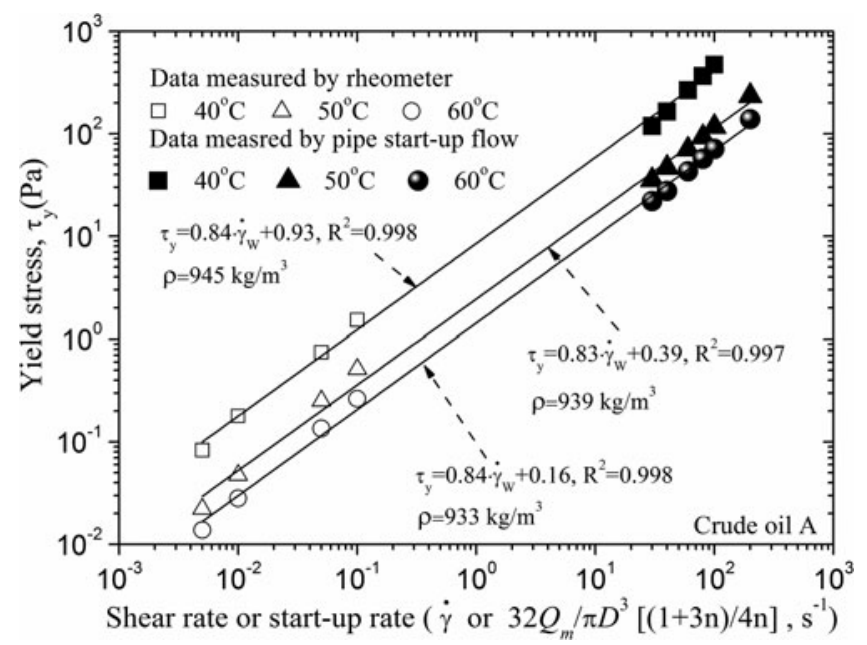

FIGURE 8 Yield stress versus start-up rate obtained in pipe start-up flow with those measured in the rheometer.

\subsection{Comparison Between the Rheological Measurements and the Data of Pipe Flow}

In a laminar flow of power-law fluid in pipes, the shear stress and start-up rate can be calculated by using Eqs. (4) and (6). Figure 8 presents that the experimental data of yield stress versus start-up rate obtained in the pipe start-up flow with those measured in the rheometer. Open symbols denote the results measured in the rheometer, and closed symbols represent the experimental data in the pipe flow. As can be observed, the value of yield stress decreases with increasing the temperature in an approximate exponential type. At a fixed temperature, the yield stress versus start-up rate obtained by two systems shows a fine liner relationship. The regression correlation coefficient $\left(\mathrm{R}^{2}\right)$ is larger than 0.997 . Note that in the pipe transportation of heavy crude oil, the start-up rate is usually located in the domain of high shear rates. Therefore, the yield stress of the heavy crude oil can be predicted on the basis of laboratory rheological measurements by this liner relationship. These results demonstrate that the transport characteristics of heavy crude oil can be predicted successfully by the rheological measurements.

\section{CONCLUSIONS}

An experimental study on flow characteristics of heavy crude oil for pipeline transportation has been carried out. On the basis of experimental results and analysis, the following conclusions can be obtained.

The yield stress measured by the rheometer increases linearly with increasing the shear rate, and displays an exponential decay with increasing the temperature. In addition, there is an approximate linear relationship between the yield stress and the area of thixotropic loop independent to the temperature and crude oil types. A comparison between the experimental data obtained in pipe start-up flow with those measured in the rheometer shows a fine liner relationship. Therefore, our research reveals that the transport characteristics of heavy crude oil can be predicted successfully by the rheological measurements. 


\section{REFERENCES}

Barnes, H. A. (1999). The yield stress - a review or ' $\pi \alpha \nu \tau \alpha \rho \varepsilon \iota$ ' - everything flows? J. Non-Newtonian Fluid Mech. 81:133-178.

Dehkissia, S., Larachi, F., Rodrigue, D., and Chornet, E. (2004). Characterization of Doba-Chad heavy crude oil in relation with the feasibility of pipeline transportation. Fuel 83:2157-2168.

Escudier, M. P., and Presti, F. (1996). Pipe flow of a thixotropic liquid. J. Non-Newtonian Fluid Mech. 62:291-306.

Martinez-Palou, R., Mosqueira, M. L., Zapata-Rendon, B., Mar-Juarez, E., Bernal-Huicochea, C., Clavel-Lopez, J. C., and Aburto, J. (2011). Tansportation of heavy and extra-heavy crude oil by pipeline: A review. J. Pet. Sci. Eng. 75:274-282.

Mortazavi-Manesh, S., and Shaw, J. M. (2014). Thixotropic rheological behavior of Maya crude oil. Energy Fuels 28:972-979.

Zhang, J., Xu, J. Y., and Gao, M. C. (2014). Experimental investigation on yield stress of water in heavy crude oil emulsions in order to improve pipeline flow. J. Dispers. Sci. Technol. 35:593-598. 